\title{
Outcome of strabismus surgery in congenital esotropia
}

\author{
J M Keenan, H E Willshaw
}

\begin{abstract}
The results of squint surgery in $\mathbf{4 0}$ children with congenital esotropia are analysed. A 'favourable outcome' was achieved in 23 $(57 \cdot 5 \%)$ children. The factors affecting the final outcome including ocular alignment in the immediate postoperative period, age at the time of surgery, amblyopia, associated inferior oblique overaction, dissociated vertical deviation, latent or manifest latent nystagmus, and the surgical procedures used are discussed.
\end{abstract}

Congenital esotropia is an esodeviation with an onset before 6 months of age, ${ }^{1}$ characterised by a large stable angle, a limited potential for binocular single vision, and an association with oblique muscle dysfunction, dissociated vertical deviation (DVD), and latent or manifest latent nystagmus. ${ }^{2}$ The results of surgery in congenital esotropia have been classified by von Noorden ${ }^{2}$ into (1) orthotropia or asymptomatic heterophoria with subnormal binocular vision, (2) microtropia, (3) small angle ( $<20$ dioptres) and cosmetically acceptable residual esotropia or consecutive exotropia, and (4) large angle $(>20$ dioptres) residual esotropia or consecutive exotropia that requires additional surgery. However others have categorised as cosmetically acceptable only those aligned within 10 dioptres of straight and furthermore alignment within 10 dioptres of straight prior to 24 months of age may significantly improve the prospects of developing binocular single vision. ${ }^{3}$

The initial surgical procedures used to attain alignment include monocular recessionresection, ${ }^{4}$ bimedial rectus recessions, ${ }^{5}$ and three and four horizontal muscle surgery, ${ }^{6}$ any of which may be combined with conjunctival recessions $^{7}$ and/or inferior oblique muscle surgery. ${ }^{8}$

We reviewed children under our care who underwent surgery for congenital esotropia, and who had a follow-up of at least 2 years, to determine the results achieved, to identify the factors associated with satisfactory and less satisfactory outcomes, and to consider this information in the planning of future surgery for this condition.

Department of Paediatric Ophthalmology, Birmingham Children's Hospital, Ladywood Middleway, Birmingham B16 8ET

J M Keenan

HE Willshaw

Correspondence to: J M Keenan, FRCS FCOphth. Accepted for publication 17 October 1991

\section{Patients and methods}

The case notes of consecutive patients undergoing surgery for congenital esotropia at the Children's Hospital, Birmingham, in the 5 year period between January 1982 and December 1986 were reviewed. Congenital esotropia was defined as the onset of esotropia in the first 6 months of life, with no significant accommodative component. ${ }^{y}$ Any patient with a neurological deficit or ocular pathology and all those with a follow-up of less than 24 months were excluded. Information was obtained from the preoperative examination and from examinations at 2 weeks, at 3-6 months, and at yearly intervals thereafter until discharge.

Amblyopia was defined as a difference of two lines or more between the monocular visual acuities using appropriate correction where necessary. Anisometropia was defined as a spherical or cylindrical difference of more than 1.0 dioptre between the two eyes. ${ }^{10}$ All refractions were undertaken under cycloplegia using either cyclopentolate or atropine.

Statistical analysis was performed using medians and the non-parametric Mann-Whitney test for comparing continuous variables, and the $\chi^{2}$ test with Yates' correction or Fisher's exact test for categorial data.

\section{Results}

The inclusion criteria were met by 40 patients. There was an equal male/female sex distribution. The age at surgery ranged from 8 to 71 months (median 21 months), the preoperative squint angle from +25 to +60 dioptres (median +50 dioptres), and the postoperative follow-up from 24 to 83 months (median 44.5 months). The surgery undertaken is detailed in Table 1 .

The final alignment obtained for the whole group is detailed in Table 2 . A single operation was performed for 26 children $(65 \%)$, and a second procedure was carried out for the remaining $14(35 \%)$. A residual esotropia of more than 20 dioptres was present in four patients; two were considered cosmetically acceptable and two were scheduled for further squint surgery.

There was evidence of binocular single vision postoperatively in 11 patients $(27 \cdot 5 \%)$; nine showed motor fusion and two gross stereopsis demonstrable with the synoptophore. The final

Table 1 Surgical procedures with numbers of cases (and percentages) undertaken for congenital esotropia

\begin{tabular}{|c|c|}
\hline S recessions & 15 \\
\hline $\begin{array}{l}\text { al } \\
\text { nyectomies }\end{array}$ & 7 \\
\hline $\begin{array}{l}\text { imed } \\
\text { reces }\end{array}$ & \\
\hline h hilateral inf & 5 \\
\hline al rectus & \\
\hline th faden sutures and & $1 \quad(2 \cdot 5 \%)$ \\
\hline Monocular medial rec & \\
\hline
\end{tabular}

Table 2 Final alignment obtained in 40 children with congenital esotropia

Within \pm 10 dioptres of straight More than +20 dioptres 
Table 3 Postoperative squint angles in the favourable and less favourable outcome groups at 3-6 months postoperatively $(p=0.042)$

\begin{tabular}{llll}
\hline & $\begin{array}{l}\text { Favourable } \\
\text { outcome }\end{array}$ & $\begin{array}{l}\text { Less } \\
\text { favourable } \\
\text { outcome }\end{array}$ & $\begin{array}{l}\text { Row } \\
\text { total }\end{array}$ \\
Postoperative squint angle & 19 & 8 & 27 \\
\hline Within \pm 15 dioptres of & & 9 & 13 \\
straight & 4 & 17 & 40 \\
More than \pm 15 dioptres & 23 & & \\
Column total & & & \\
\hline
\end{tabular}

alignment was within \pm 10 dioptres of straight in eight of these patients; two had a consecutive exotropia of 14 dioptres and one a residual esotropia of 20 dioptres. A final alignment within \pm 10 dioptres of straight was also present in 12 patients who showed no evidence of binocular single vision postoperatively.

A 'favourable outcome' was considered to be present in $23(57 \cdot 5 \%)$ children. There was evidence of binocular single vision in 11 (the final alignment was within \pm 10 dioptres of straight in eight of these patients; two had a consecutive exotropia of 14 dioptres and one a residual esotropia of 20 dioptres); and the remaining 12 patients had a final alignment within \pm 10 dioptres of straight with no evidence of binocular single vision.

\section{POSTOPERATIVE ALIGNMENT}

When the 23 patients with a favourable outcome were compared with the 17 patients with a less favourable outcome, no significant difference was found between the median age at onset of squint (1 month vs at birth), median age at surgery (19 vs 27 months), median preoperative squint angle ( +50 dioptres in both groups), incidence of amblyopia at the time of surgery $(21.7$ vs $23.5 \%)$, incidence of anisometropia ( $26 \cdot 1$ vs $17 \cdot 6 \%$ ), or incidence of further surgery $(30 \cdot 4$ vs $41 \cdot 2 \%)$. The only difference between the two groups was in the postoperative squint angle measurement at 3-6 months, with significantly more of the favourable outcome group achieving alignment within \pm 15 dioptres of straight at that time (Table 3).

Ocular alignment at the first postoperative visit was not found to be a reliable predictor of favourable outcome. Furthermore, in 10 patients the strabismus angle changed by more than 10 dioptres between the first and second postoperative examinations; seven children with residual esotropia showed a reduction in their esotropia, one child with residual esotropia increased, and the only two children with an immediate consecutive exotropia showed an increase in their divergent angle.

\section{EARLY SURGERY}

Squint surgery was performed in 23 patients before their second birthday, with $16(69 \cdot 6 \%)$ of these children achieving a favourable outcome, compared to a favourable outcome in seven of 17 children $(41 \cdot 2 \%)$ whose surgery was performed after their second birthday.

Alignment within \pm 15 dioptres of straight at the 3-6 month postoperative examination was present in 11 of the early surgery group prior to their second birthday, and nine of these 11 patients $(81 \cdot 8 \%)$ achieved a favourable outcome.
Alignment within \pm 15 dioptres of straight at the 3-6 months postoperative examination was present in a further 16 patients after their second birthday (eight of these patients were in the early surgery group but were not aligned until after their second birthday), and a favourable outcome was achieved in 10 of these 16 patients $(62 \cdot 5 \%)$. These results did not achieve statistical significance.

\section{AMBLYOPIA}

Amblyopia treatment was required in 26 patients $(65 \%)$ prior to surgery, nine of whom remained amblyopic at the time of surgery. In the group of 17 patients who had their amblyopia successfully reversed prior to surgery a favourable outcome was present in nine $(52.9 \%)$. In the nine patients who remained amblyopic at the time of surgery a favourable outcome was present in only three $(33 \cdot 3 \%)$.

Nine patients not amblyopic at the time of surgery required postoperative amblyopia treatment; six of these had received preoperative amblyopia treatment, but in three there was no history of preoperative amblyopia. Despite requiring postoperative amblyopia treatment six of these nine patients $(66.6 \%)$ still achieved a favourable outcome.

Anisometropia was present in eight patients preoperatively, six of whom required amblyopia treatment. Three remained amblyopic at the time of surgery; one had a hypermetropic cylindrical anisometropia and two a combined hypermetropic spherical and cylindrical anisometropia. Postoperatively a favourable outcome was achieved in five of the nine patients $(55 \cdot 6 \%)$.

INFERIOR OBLIQUE OVERACTION, DVD, LATENT OR MANIFEST LATENT NYSTAGMUS

Inferior oblique overaction was present in 12 patients $(30 \%)$ preoperatively, all of whom had bilateral inferior oblique myectomies combined with horizontal squint surgery. A further four patients $(10 \%)$ developed inferior oblique overaction after their initial surgery. A favourable outcome was obtained in nine of these 16 patients $(56.3 \%)$; the remainder had a residual esotropia of greater than 10 dioptres.

Dissociated vertical deviation occurred in six patients $(15 \%)$, all with onset after their initial surgery. Surgical correction was required in one. A favourable outcome was obtained in five of these patients.

Latent nystagmus (LN) was present in four patients, and one had manifest latent nystagmus (MLN). A favourable outcome was achieved in four of these patients, including the child with MLN.

\section{SURGICAL PROCEDURE}

Bimedial rectus recessions either alone or in combination with conjunctival recessions, inferior oblique myectomies, or faden sutures were used for the initial operation in 35 patients $(87 \cdot 5 \%)$.

The two main groups available for comparison 


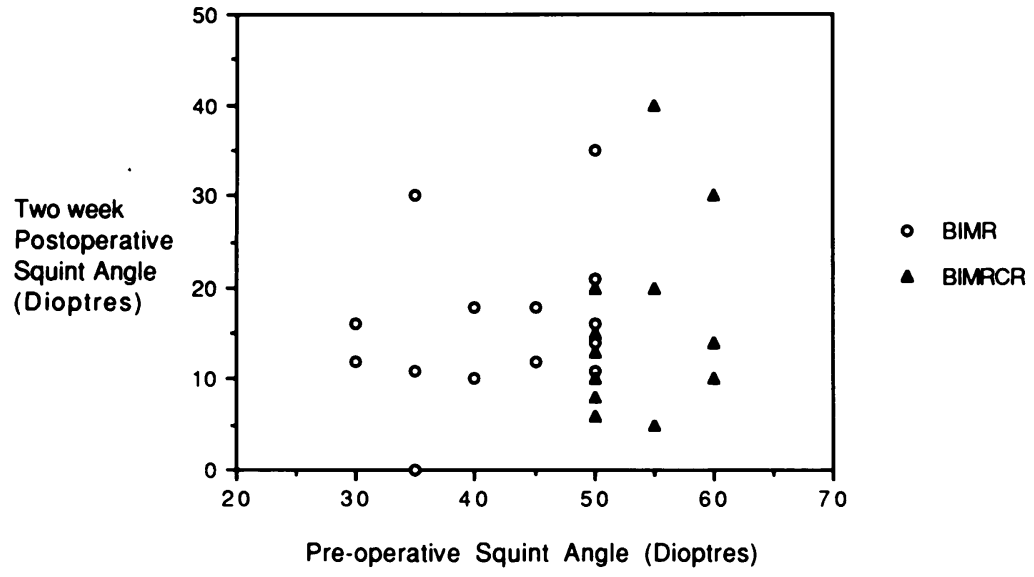

Figure 1 Relationship of the postoperative to the preoperative squint angles in 15 patients undergoing bimedial rectus recessions $(B I M R)$ and 12 patients undergoing bimedial rectus recessions with conjunctival recessions (BIMRCR).

are bimedial rectus recessions of $6 \mathrm{~mm}$ without conjunctival recessions (used for preoperative angles of 50 dioptres or less), and bimedial rectus recessions of $6 \mathrm{~mm}$ with conjunctival recessions (used for preoperative angles of 50 dioptres or more), both groups being combined with inferior oblique myectomies when required.

A comparison of the postoperative squint angle at 2 weeks in the two groups is shown in Figure 1. An increase in the preoperative squint angle in both groups is associated with an increase in the residual esotropia. For a preoperative angle of 50 dioptres where either procedure was used the group with conjunctival recessions was corrected by a median value of 4.5 dioptres more at first postoperative examination.

\section{Discussion}

Looking at the group as a whole, the best results were achieved in the children who had a squint angle within \pm 15 dioptres of straight at 3-6 months postoperatively. A favourable outcome was present in 19 of $27(70.4 \%)$ of these children compared to four of $13(30 \cdot 8 \%)$ children with a 3-6 month postoperative squint angle of greater than \pm 15 dioptres.

Furthermore if this alignment was achieved before the age of 24 months a favourable outcome occurred in nine of 11 children $(81 \cdot 8 \%)$. This is in accordance with the findings of Ing who demonstrated an improved outcome for children adequately aligned prior to their second birthday. ${ }^{3}$ An added bonus may be the improvement in the child's fine motor development and visual function following surgery. ${ }^{11}$

Amblyopia which persisted at the time of surgery was associated with a lesser percentage $(33.3 \%)$ of children with a favourable outcome when compared with children whose amblyopia was successfully reversed by the time of surgery (53\%). Anisometropia was associated with unreversed preoperative amblyopia. The onset of amblyopia postoperatively in patients not known to be amblyopic preoperatively is well recognised, ${ }^{12}$ particularly in those with a residual small angle esotropia; but in our series $66 \cdot 7 \%$ still achieved a favourable outcome following amblyopia treatment.

Inferior oblique overaction, DVD, and latent or manifest latent nystagmus are associated with congenital esotropia. They may occur in combi- nation, and one of our patients demonstrated all three. Inferior oblique overaction and DVD were present in two and latent nystagmus and DVD in three patients. There was no evidence that the presence of these disorders was associated with a less favourable outcome but the numbers of each are too small to allow a definitive statement.

Conjunctival recessions have been shown to augment the results of convergent squint surgery, and this is confirmed in Figure 1, where for equal preoperative squint angles, a greater correction is achieved with augmented or en bloc recessions. ${ }^{713}$ Inferior oblique surgery is not considered to have any significant effect on the postoperative horizontal alignment. ${ }^{14}$ The variation in the postoperative result for the same operation for an equal preoperative squint angle is also demonstrated in Figure 1, which increases the difficulty in predicting the outcome of squint surgery in the individual child.

The results suggest that an increase in the amount of surgery for any given preoperative squint angle would be appropriate. Bimedial rectus recessions of $7 \mathrm{~mm}$, which have been shown to be effective and not to cause limitation of convergence or adduction, ${ }^{15}$ or the use of conjunctival recessions, should be considered for smaller preoperative squint angles. Measurement from the limbus may be beneficial where maximal medial rectus recession is sought, as the distance of the medial rectus insertion from the limbus is variable. ${ }^{16}$

\section{Conclusion}

We have shown that the best prospects for a favourable outcome in congenital esotropia occur with alignment within \pm 15 dioptres of straight at 3-6 months postoperatively, particularly if this alignment is achieved before the second birthday. Amblyopia which persisted at the time of surgery was associated with anisometropia and with a lesser percentage of children achieving a favourable outcome. More surgery for the larger preoperative squint angles would have been appropriate. A beneficial effect from the use of conjunctival recessions was demonstrated. We therefore recommend early surgery, ideally by 18 months of age, designed to achieve alignment within \pm 15 dioptres of straight at the 3-6 month examination, and to allow secondary surgery prior to their second birthday for those children not achieving this result. Careful attention must also be directed towards reversing amblyopia and correcting significant anisometropia in the preoperative period.

The authors are grateful to Helen Jones, University Department of Ophthalmology, Birmingham, for statistical advice.

1 Nelson LB, Wagner RS, Simon JW, Harley RD. Congenital esotropia. Surv Ophthalmol 1987; 31: 363-83.

2 Von Noorden GK. Current concepts of infantile esotropia. Eye 1988; 2: 343-57.

3 Ing MR. Early surgical alignment for congenital esotropia. Ophthalmology 1983; 90: 132-5.

4 Bartley GB, Dyer JA, Ilstrup DM. Characteristics of recession-resection and bimedial recession for childhood esotropia. Arch Ophthalmol 1985; 103: 190-5.

5 Nelson LB, Calhoun JH, Simon JW, Wilson T, Harley RD. Surgical management of large angle congenital esotropia. Br fOphthalmol 1987; 71: 380-3.

6 Scott WE, Reese PD, Hirsh CR, Flabetich CA. Surgery for large-angle congenital esotropia. Two vs three and four horizontal muscles. Arch Ophthalmol 1986; 104: 374-7. 
7 Willshaw HE, Mashoudi N, Powell S. Augmented medial rectus recession in the management of esotropia. $\mathrm{Br} \mathcal{J}$ Ophthalmol 1986; 70: 840-3.

$8 \mathrm{Kraft}$ SK, Scott WE. Surgery for congenital esotropia - an age comparison study. $\mathcal{F}$ Paediatr Ophthalmol Strabismus 1984 21: 57-68. 9 Baker JD, Parks MM. Early onset accommodative esotropia.
Am f Ophthalmol 1980; 90: 11-8.

10 Moore A. In: Taylor D, Avetisov E, Baraitser M, et al eds. Paediatric Ophthalmology. Boston: Blackwell, 1990; 6970.

11 Rogers GL, Chazan S, Fellows R, Tsou BH. Strabismus surgery and its effect upon infant development in congenital surgery and its effect upon infant development
12 Ing MR. Early surgical alignment for congenital esotropia. Trans Am Ophthalmol Soc 1981; 79: 625-63.

13 Helveston EM, Ellis FD, Patterson JH, Weber J. Augmented recession of the medial recti. Ophthalmology 1978; 85: 50711.

14 Stager DR, Parks MM. Inferior oblique weakening procedures. Effect on primary position horizontal alignment. Arch Ophthalmol 1973; 90: 15-16.

15 Szmyd SM, Nelson LB, Calhoun JH, Spratt C. Large bimedial rectus recessions in congenital esotropia. $\mathrm{Br} \mathcal{F}$ Ophthalmol 1985; 69: 271-4.

16 Richler M, Barsoum-Homsy M. Bimedial rectus recession measured from the limbus for congenital esotropia. Can $\mathcal{F}$ Ophthalmol 1989; 24: 304-7. 